\title{
A Novel p75NTR Signaling Pathway Promotes Survival, Not Death, of Immunopurified Neocortical Subplate Neurons
}

\author{
Michael F. DeFreitas, ${ }^{1}$ Patrick S. McQuillen, ${ }^{2}$ and Carla J. Shatz ${ }^{1}$ \\ ${ }^{1}$ Department of Neurobiology, Harvard Medical School, Boston, Massachusetts 02115, and 2Department of Pediatrics, \\ University of California, San Francisco Medical Center, San Francisco, California 94143
}

Subplate neurons of mammalian neocortex undergo pronounced cell death postnatally, long after they have matured and become incorporated into functional cortical circuits. They express the p75 neurotrophin receptor (p75NTR), which is known to signal cell death in some types of neurons via the activation of sphingomyelinase and the concomitant increase in the sphingolipid ceramide. To evaluate the role of p75NTR in subplate neurons, they were immunopurified and cultured in vitro. Contrary to its known function as a death receptor, ligand binding to p75NTR promotes subplate neuron survival. Moreover, p75NTR-dependent survival is blocked by inhibition of ceramide synthesis and rescued by addition of its precursor sphingomyelin. Inhibition of Trk signaling does not block survival, nor is Trk signaling alone sufficient to promote survival. Thus, ligand-dependent p75NTR regulation of the ceramide pathway mediates survival in certain neurons and may represent an important target for neuroprotective drugs in degenerative diseases involving p75NTR-expressing neurons, such as Alzheimer's disease.

Key words: subplate neurons; p75 neurotrophin receptor; survival; ceramide; BDNF; immunopurification
Subplate neurons are among the earliest-generated neurons of developing cerebral cortex and form the deepest layer below the developing cortical plate (Allendoerfer and Shatz, 1994). They are the first cortical neurons to differentiate and become incorporated into functional neuronal circuits, where they are needed for the establishment of thalamocortical connections (Friauf et al., 1990; Ghosh et al., 1990; Ghosh and Shatz, 1993). However, unlike later-generated cortical neurons, large numbers of subplate neurons undergo programmed cell death during early postnatal development (Allendoerfer and Shatz, 1994; Spreafico et al., 1995; Price et al., 1997). This raises the question of how a mature population of CNS neurons that is fully integrated into a functioning circuit are selectively eliminated, and conversely, what signal transduction pathways control their survival.

Neuronal survival throughout the peripheral nervous system (PNS) is primarily controlled by neurotrophins interacting with two types of neurotrophin receptors: the ligand-selective Trk tyrosine kinases and the nonselective p75 neurotrophin receptor (p75NTR) (Barbacid, 1995; Conover and Yancopoulos, 1997; Chao et al., 1998). Trk receptors play a critical role in promoting the survival of many PNS neurons via activation of their tyrosine kinase domains. In contrast, the role of p75NTR in neuronal survival is cell-type dependent. From studies of knock-out mice,

Received Oct. 17, 2000; revised March 1, 2001; accepted May 1, 2001.

This research was supported by National Eye Institute Grants EY02858 (C.J.S.) and F32 EY06602 (M.F.D.), National Institutes of Health Grant K12HD00850 (P.S.M.), and University of California, San Francisco Child Health Research Center-National Institute of Child Health and Human Development Grant HD28825-07 (P.S.M.). We thank Louis Reichardt, Eric Shooter, and MarkBothwell for the anti-p75NTR antibodies, Cynthia Cowdrey for preparing the cryostat sections, Claire McKellar for assisting with subplate purifications, Ben Barres for technical advice on the immunopanning protocol, and both Ben Barres and Michael Greenberg for reading this manuscript and providing valuable feedback.

Correspondence should be addressed to Carla J. Shatz, Department of Neurobiology, Harvard Medical School, 220 Longwood Avenue, 405 Goldensen Building, Boston, MA 02115. E-mail: carla_shatz@hms.harvard.edu.

Copyright (C) 2001 Society for Neuroscience $\quad 0270-6474 / 01 / 215121-09 \$ 15.00 / 0$
p75NTR is known to be required for survival of nociceptive sensory neurons, although it mediates naturally occurring cell death of sympathetic and certain motor neurons (Lee et al., 1992; Bamji et al., 1998; Brennan et al., 1999; Frade and Barde, 1999). In vitro, $\mathrm{p} 75 \mathrm{NTR}$ has been found to mediate neuronal survival by facilitating Trk signaling at low neurotrophin concentrations (Davies et al., 1993; Lee et al., 1994). Death, on the other hand, is thought to result from p75NTR signaling in the absence of Trk activation (Carter and Lewin, 1997; Dechant and Barde, 1997; Yoon et al., 1998). This leads to ceramide production, which in turn activates an apoptotic signaling cascade (Casaccia-Bonnefil et al., 1996; Hannun, 1996).

Analysis of mice deficient in neurotrophins or their receptors also argues for neurotrophin-dependent survival of certain populations of cerebral cortical neurons (Minichiello and Klein, 1996; Alcántara et al., 1997; Chen et al., 1997; Fagan et al., 1997; Peterson et al., 1999). However, because neurotrophins also regulate axon outgrowth, it is unclear from these in vivo studies whether the neurotrophins and their receptors promote survival by acting directly on the neurons of interest, or whether they indirectly promote survival by affecting other cell types or even target innervation. p75NTR, as well as TrkB, is expressed by subplate neurons (Allendoerfer et al., 1990; Cabelli et al., 1996). Whereas TrkB is also expressed by neurons of all other cortical layers, p75NTR expression within developing neocortex is highly restricted to the subplate (Koh and Loy, 1989; Allendoerfer et al., 1990; Meinecke and Rakic, 1993). Given the link between p75NTR and cell death in the PNS (Carter and Lewin, 1997; Dechant and Barde, 1997; Chao et al., 1998), we hypothesized that the selective loss of subplate neurons could be explained by the restricted expression of p75NTR and activation of its associated apoptotic signaling pathways. To study the role of p75NTR and its associated signal transduction pathways on subplate neuron survival, we used immunopanning techniques to purify these neurons. This novel purification of subplate neurons allowed us to 
determine the direct effect of p75NTR and its signaling pathways on their survival in a less complicated cellular environment. Surprisingly, we found that ligand binding to p75NTR promotes survival, not death, of cultured subplate neurons and that this survival is blocked by drugs that inhibit the synthesis of ceramide, identified previously as an apoptotic signal.

\section{MATERIALS AND METHODS}

Subplate neuron purification. All reagents were purchased from Sigma (St. Louis, MO) unless otherwise noted. The immunopanning plate was coated with goat anti-mouse (Jackson ImmunoResearch, West Grove, PA) as described by Barres et al. (1988) and then coated with 0.55 $\mu \mathrm{g} / \mathrm{cm}^{2}$ anti-p75NTR monoclonal antibody 192 (mAb 192) in HBSS (Mediatech Inc., Ormond Beach, FL) with $10 \%$ fetal bovine serum. mAb 192 (Chandler et al., 1984) was the generous gift of Eric Shooter (Stanford University, Stanford, CA). Brains from embryonic day 17 (E17) (day of breeding is E0) Long-Evans rats (Simonsen Laboratories, Gilroy, CA) were dissected on ice in HBSS. Meninges were removed, and dorsolateral caudal neocortex was digested in $23 \mathrm{U} / \mathrm{ml}$ papain (Worthington, Freehold, NJ) and $10 \mu \mathrm{g} / \mathrm{ml}$ DNase I as described by Huettner and Baughman (1986). Digestion was stopped with $10 \mu \mathrm{g} / \mathrm{ml}$ antipain. Dissociated cells were centrifuged through a 15\%/60\% Percoll (Amersham Pharmacia Biotech, Uppsala, Sweden) step gradient for $5 \mathrm{~min}$ at $400 \times \mathrm{g}$, and cells were collected at the $15 \% / 60 \%$ Percoll interface. After a 30 min recovery, cells were applied to the mAb 192-coated immunopanning plate $\left(\sim 1 \times 10^{8}\right.$ cells per plate $)$ and allowed to attach for $20 \mathrm{~min}$ at $4^{\circ} \mathrm{C}$. After four washes to remove unbound cells, the bound cells were removed by digestion with saline- $0.05 \%$ trypsin-versene (University of California, San Francisco Cell Culture Facility) for 5 min. Resultant cells were washed and cultured in Neurobasal medium with B-27 additives (Life Technologies, Gaithersburg, MD) and penicillin-streptomycin on tissue culture plastic coated with $1 \mathrm{mg} / \mathrm{ml}$ poly-ornithine and $15 \mu \mathrm{g} / \mathrm{ml}$ fibronectin (Becton Dickinson, Mountain View, CA) in calcium, magnesiumfree-PBS.

In situ hybridization. In situ hybridization was performed as described by Corriveau et al. (1998), using probes specific for rodent p75NTR, TrkA, TrkB, and TrkC. Murine clones were obtained from either cDNA produced from RNA from embryonic (E18) mouse spinal cord or neonatal mouse brain. The PCR primers used for amplification of mouse fragments were designed from published sequences and were as follows: p75NTR, 5'-TGACCACTGTGATGGGCAG-3' and 5'-GCCTCGTGGGTAAAGGAGTC-3'; TrkA， 5'-CTAGGCGGTCTGGTGACTTC-3' and 5'-CTTCCACAGAGTCATTGGGC-3'; TrkB, 5'-CGGCACATAAATTTCACACG-3' and 5'-ACAGTGAATGGAATGCACCA3'; and TrkC, 5'-CGAAGACAATGGTTTCACCCTGAC-3' and 5'CAACTGCTATGGACACCCCAAAAG-3'. Amplified fragments were gel purified and cloned into pBSII-KS vector. Plasmids were sequenced to verify the product. Antisense riboprobes produced from these cDNAs of p75NTR and the Trks hybridize to the extracellular regions of each of these receptors (Radeke et al., 1987; Klein et al., 1989; Kaplan et al., 1991; Lamballe et al., 1991). Sense controls showed no hybridization signal.

BrdU birth dating. Animals were used in accordance with University of California guidelines for animal usage. Long-Evans rats, 12 or $15 \mathrm{~d}$ pregnant, were injected intraperitoneally with $35 \mathrm{mg} / \mathrm{kg}$ 5-bromo-2deoxyuridine (BrdU). To detect BrdU in situ, cryostat sections were microwaved in $0.05 \mathrm{M}$ citrate, $\mathrm{pH} 5.0$, for $14 \mathrm{~min}$ and incubated with $100 \mathrm{U} / \mathrm{ml}$ Exo III and anti-BrdU monoclonal IU-4 (Caltag, South San Francisco, CA). Bound antibody was detected with HRP-conjugated anti-mouse (Jackson ImmunoResearch), followed by FITC-tyramide (NEN, Boston, MA). Sections were counterstained with bisbenzimide. To detect BrdU in culture, cells grown for $15 \mathrm{hr}$ were fixed in $95 \%$ ethanol $-5 \%$ acetic acid at $-20^{\circ} \mathrm{C}$ for $15 \mathrm{~min}$ and incubated with $2 \mathrm{~N} \mathrm{HCl}$ for $40 \mathrm{~min}$ at room temperature. BrdU immunohistochemistry was done according to standard protocols using IU-4 and Cy3-conjugated donkey anti-mouse (1:200; Jackson ImmunoResearch) with bisbenzimide as a nuclear counterstain. Percentage of BrdU-labeled cells was determined by counting $>200$ cells from randomly chosen fields from three separate preparations and dividing by the total number of bisbenzimide-labeled nuclei. Results are mean \pm SEM.

Immunohistochemistry. Bound and unbound cells were cultured for either 1 or $15 \mathrm{hr}$ and fixed with $95 \%$ ethanol $-5 \%$ acetic acid at $-20^{\circ} \mathrm{C}$ for $15 \mathrm{~min}$. Cells were stained by standard immunofluorescent staining protocols using anti-Tau sera (catalog \#T6402; Sigma), anti-vimentin (clone V9; Boehringer Mannheim, Mannheim, Germany), anti-nestin (catalog \#MAB353; Chemicon, Temecula, CA), or anti-p75NTR (catalog \#G3231; Promega, Madison, WI). For visualization, secondary antibodies used included Cy3-conjugated donkey anti-mouse or anti-rabbit (1:200; Jackson ImmunoResearch) or Alexa488-conjugated anti-mouse (1:200; Molecular Probes, Eugene, OR). Bisbenzimide counterstain was used to count the total number of cells.

Survival assays. Subplate neurons were cultured in 48 well dishes for 3-4 d in Neurobasal medium and B-27 additives with or without added neurotrophins: mouse NGF, recombinant human BDNF, and recombinant human neurotrophin 3 (NT3) (Alomone Labs, Jerusalem, Israel). Survival was measured using the Live/Dead Assay (Molecular Probes). Two counts of $>100$ cells each were made from random fields of each well. Each experiment was done in duplicate and repeated at least three times, and the results were averaged. All reagents added to the cultures were added at the time of plating for the extent of the experiment. Reagents used were as follows: K252a (Alomone Labs) at $200 \mathrm{~nm}$, anti-p75NTR FAbs antibodies and normal rabbit FAbs at $200 \mu \mathrm{g} / \mathrm{ml}$, excess NGF at $3 \mu \mathrm{g} / \mathrm{ml}$, fumonisin B1 at $10 \mu \mathrm{M}$ (Biomol, Plymouth Meeting, PA), myriocin at $50 \mathrm{~nm}$ (Biomol), and C-6 sphingomyelin (Matreya Inc., Pleasant Gap, PA) at $0.3 \mu \mathrm{M}$. Function-blocking antip75NTR antisera (Weskamp and Reichardt, 1991) was the generous gift of Louis Reichardt (University of California, San Francisco). IgG was purified from this antisera with protein G Sepharose (Amersham Pharmacia Biotech). FAb fragments were prepared using immobilized papain (Pierce, Rockford, IL). For treatment with FAbs, sphingolipids, and sphingolipid synthesis inhibitors, neurotrophins were used at $30 \mathrm{ng} / \mathrm{ml}$. For NGF competition, BDNF was used at $3 \mathrm{ng} / \mathrm{ml}$.

Detection of phosphorylated Trk and mitogen-activated protein kinase. Subplate neurons cultured for $24 \mathrm{hr}$ were treated with $100 \mathrm{ng} / \mathrm{ml}$ neurotrophin for $40 \mathrm{~min}$ for detection of phosphorylated mitogen-activated protein kinase (MAPK) or for 5 min for detection of phosphorylated Trk. To block Trk signaling, neurons were incubated with $200 \mathrm{nM} \mathrm{K} 252 \mathrm{a}$ for $1 \mathrm{hr}$ before addition of neurotrophin. Equal numbers of neurons were extracted with $30 \mu \mathrm{l}$ of extraction buffer $(20 \mathrm{~mm}$ Tris, $\mathrm{pH} 7.5,250 \mathrm{~mm}$ $\mathrm{NaCl}, 0.5 \%$ Triton X-100, $3 \mathrm{~mm}$ EGTA, $3 \mathrm{~mm}$ EDTA, $20 \mathrm{~mm}$ $\beta$-glycerophosphate, $0.1 \mathrm{~mm} \mathrm{NaVO}_{4}, 50 \mathrm{~mm} \mathrm{NaF}, 5 \mu \mathrm{g} / \mathrm{ml}$ chymostatin, $5 \mu \mathrm{g} / \mathrm{ml}$ leupeptin, $5 \mu \mathrm{g} / \mathrm{ml}$ antipain and $5 \mu \mathrm{g} / \mathrm{ml}$ pepstatin, and $1 \mathrm{~mm}$ PMSF) and scraped off the culture dish. Extracts were spun at 10,000 rpm for $10 \mathrm{~min}$. Equal amounts of supernatant were analyzed by SDSPAGE and standard immunoblotting techniques. Nitrocellulose blots (Schleicher \& Schuell, Dassel, Germany) were blocked with Superblotto (Pierce) and incubated with a 1:5000 dilution of anti-active MAPK (catalog \#V6671; Promega) or with a 1:750 dilution of anti-phosphoTrkA (Tyr490) [(catalog \#9141S; New England Biolabs, Beverly, MA) this antibody cross-reacts with phosphorylated TrkB and TrkC]. The secondary antibody was 1:10,000 HRP-conjugated donkey anti-rabbit (Jackson ImmunoResearch). Blots were visualized by enhanced chemiluminescence (NEN).

\section{RESULTS}

\section{Subplate neurons express p75NTR and Trks}

Subplate-restricted expression of p75NTR, as well as coexpression of Trks, was revealed by in situ hybridization using Trk and p75NTR-specific $\left[{ }^{35} \mathrm{~S}\right]$-riboprobes on sections of E17 rat cerebral cortex (Fig. 1). Subplate neurons were labeled with a pulse of BrdU at E12, when they are undergoing their final round of cell division. Because subplate and marginal zone neurons are the only cortical neurons that become postmitotic on E12 in rat, they are the only cells subsequently heavily labeled with BrdU (Fig. 1) (Bayer and Altman, 1990). Note that, because subplate neurons in rat are generated over a period of several days (E12-E15), only a fraction of them are heavily labeled by a single injection of BrdU. p75NTR expression is restricted to the meninges and the subplate zone and colocalizes with the region of heavily BrdUlabeled subplate neurons. On the other hand, TrkB and TrkC are expressed throughout the cortical plate, the subplate, and the ventricular zone. In contrast, TrkA is not detected in cortex at this age. Thus, whereas TrkB and TrkC are expressed by many postmitotic neurons, embryonic expression of p75NTR is restricted to those neurons known to later undergo programmed cell death. 


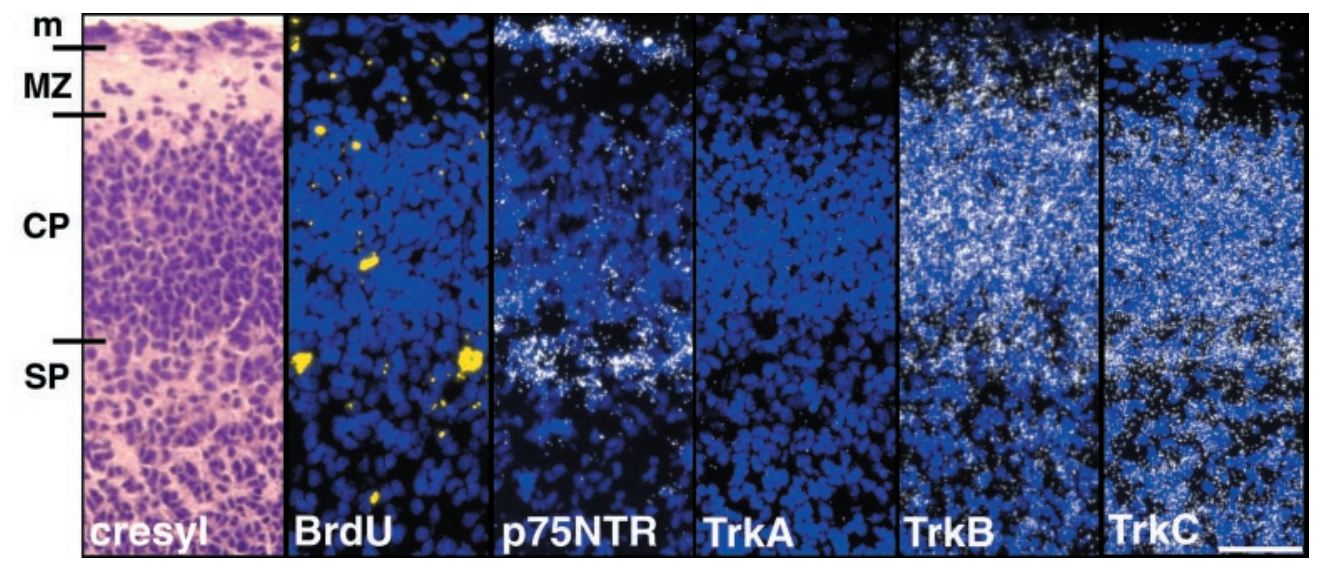

Figure 1. Subplate neurons, but not neurons of the cortical plate, express p75NTR. Localization of mRNA for p75NTR, TrkA, TrkB, and TrkC on parasagittal sections of E17 rat brain. For localization of the subplate neurons, comparable sections were stained with cresyl violet or with an antibody to BrdU. BrdU was given at E12 to label earliest-generated subplate and marginal zone neurons. Heaviest BrdUlabeled cells are restricted to marginal zone and the subplate. Note that subplate neurons are the only p75NTRexpressing neurons at this age. $m$, Meninges; $M Z$, marginal zone; $C P$, cortical plate; $S P$, subplate. Scale bar, $100 \mu \mathrm{m}$.

\section{Purification and identification of subplate neurons in culture}

To evaluate the function of p75NTR in subplate neurons, they were immunopurified based on their restricted expression of p75NTR and then cultured under serum-free conditions at low density in vitro. This approach permits the study of the direct function of p75NTR, as well as the analysis of p75NTR signaling pathways in the absence of other cell types. The majority of immunopurified cells have a pyramidal morphology, typical of subplate neurons in vivo (Friauf et al., 1990; Allendoerfer and Shatz, 1994), and readily extend processes on a fibronectin substrate in vitro (Fig. $2 a$ ). BrdU birth dating and immunocytochemistry for neuronal and non-neuronal cell markers confirm the identity of the panned cells as subplate neurons. A pulse of BrdU given at E12, a time when only subplate and marginal zone neurons are generated (Bayer and Altman, 1990), labels 33\% of the immunopurified cells (recall that a pulse of BrdU will only label a fraction of all subplate neurons), whereas only $10 \%$ of the unbound cells are BrdU labeled (Fig. 2b). Conversely, a pulse label of BrdU at E15, a time when most neurons being born are destined for layer VI rather than the subplate (Bayer and Altman, 1990), labels only $16 \%$ of the immunopurified cells versus $45 \%$ of the unbound cells. Thus, the birth date of the purified cells coincides with that of subplate neurons. The panned cells were also characterized by immunostaining with antibodies to intermediate filaments: Tau, vimentin, and nestin. In E17 cortex, these are markers for neurons, radial glia and endothelial cells, or neuroblasts, respectively (Schnitzer et al., 1981; Bignami et al., 1982; Ferreira et al., 1987; Lendahl et al., 1990). Whereas the unbound cells consist of approximately equal amounts of Tau-, vimentin-, and nestin-positive cells, the immunopurified cells are $90 \%$ neuronal based on Tau staining (Fig. 2c). The remaining $10 \%$ are mostly vimentin-positive cells that likely represent blood vessel endothelial cells, because p75NTR antibodies recognize blood vessels as well as subplate neurons in embryonic cortex (Koh and Loy, 1989; Allendoerfer et al., 1990). However, these and the $<1 \%$ contaminating nestin-positive cells are easily distinguished from the neurons by morphology, and most are not viable in the serum-free culture medium used here (data not shown). p75NTR expression, although at low levels by immunostaining, was also found on almost all of the panned cells in culture (Fig. 2c). Based on their neuronal phenotype, birth date, and expression of p75NTR, 90\% of the immunopurified cells are subplate neurons. This represents the first purification of a lamina-specific population of neocortical neurons.

\section{p75NTR promotes survival of cultured subplate neurons}

The function of p75NTR was assayed in subplate neurons cultured in the presence or absence of exogenous neurotrophins. In the absence of exogenous neurotrophins, $60-85 \%$ of subplate neurons die after $4 \mathrm{~d}$ in culture. As shown below, this loss likely reflects the lack of trophic factors. However, an alternative possibility is that p75NTR is aggregated and consequently activated by the antibody used in the panning procedure, thereby resulting in the slow cell death seen in culture. We consider this possibility highly unlikely because the monoclonal antibody used in panning [mAb 192 (Chandler et al., 1984)] does not affect survival of subplate neurons when either added to the culture medium or used as a substrate for cell attachment (data not shown). Addition of exogenous BDNF increases survival approximately twofold over control cultures (Fig. 3a,b). Survival was dose dependent and required a concentration of $0.3 \mathrm{ng} / \mathrm{ml}$ for maximal response (Fig. $3 b$ ). To test directly the role of p75NTR in BDNF-mediated survival, FAb fragments of a polyclonal antibody to the extracellular domain of p75NTR were used to block BDNF binding (Weskamp and Reichardt, 1991). Anti-p75NTR FAb fragments completely inhibit BDNF-mediated survival but have no effect on the basal survival of subplate neurons (Fig. 3a). Normal rabbit FAbs are without effect. Thus, BDNF binding to p75NTR is necessary for BDNF-mediated survival.

Because p75NTR is known to bind all neurotrophins with similar affinity (Chao et al., 1998), the effects of NGF and NT3 on subplate neuron survival were also examined. NT3, like BDNF, increases subplate neuron survival approximately twofold (Fig. $3 c$ ). NGF, on the other hand, has no significant effect on subplate neuron survival. However, when used in excess, NGF blocks BDNF-dependent survival (Fig. 3d). This observation suggests that NGF competes with BDNF for binding to p75NTR and is consistent with the model that BDNF binding to p75NTR is required for BDNF-dependent survival. Importantly, NGF does not cause significant cell death, despite the fact that subplate neurons do not express the Trk receptor for NGF, TrkA. These observations differ significantly from results in sympathetic neurons and oligodendrocytes, in which p75NTR signaling promotes cell death in the absence of activated TrkA receptors (Bamji et al., 1998; Yoon et al., 1998). Coaddition of saturating amounts of both BDNF and NT3 does not increase subplate neuron survival above that with either factor alone (Fig. 3c). Therefore, BDNF and NT3 must act on the same population of neurons, possibly via similar mechanisms. 

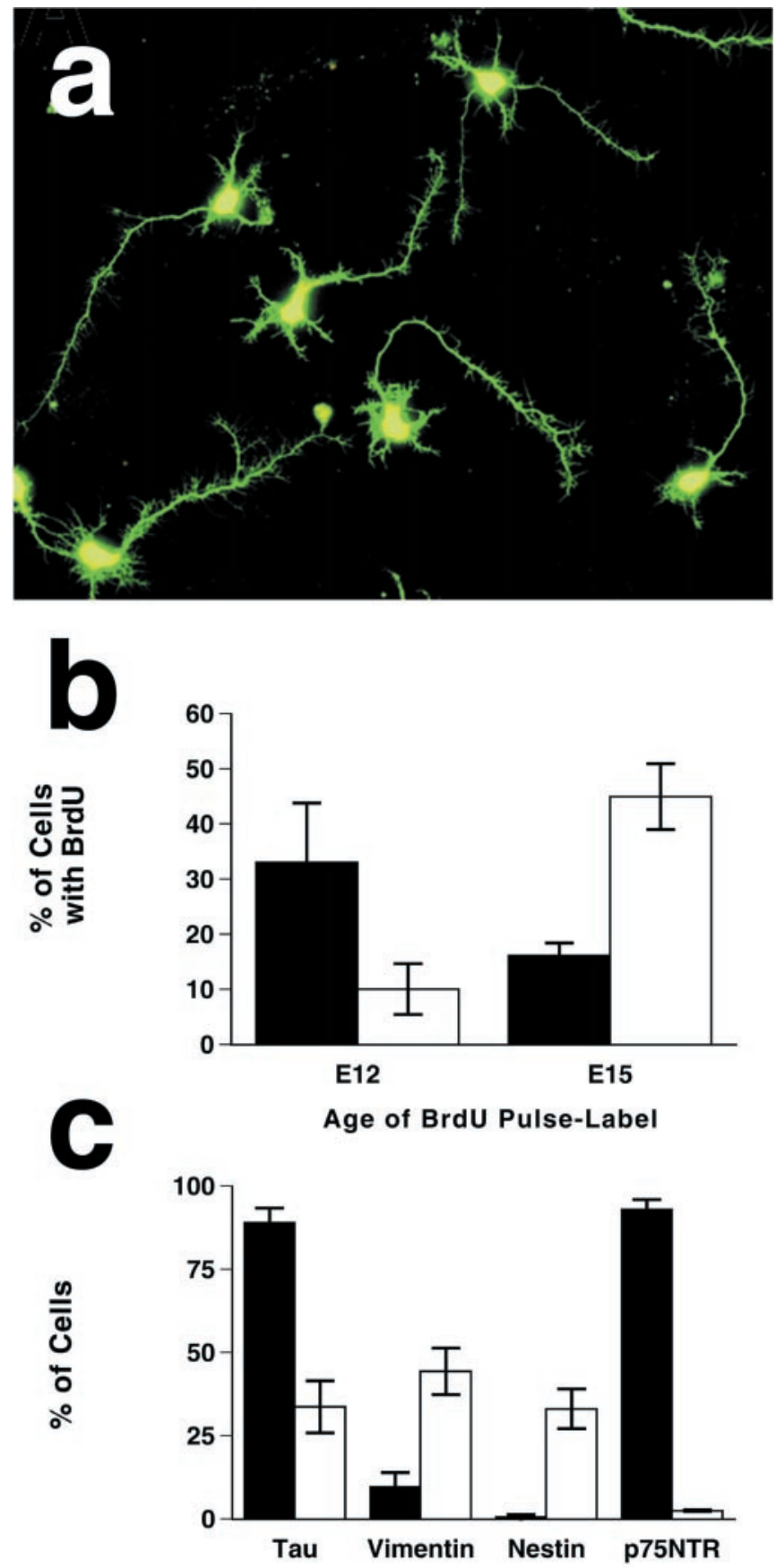

Figure 2. Immunopurification of subplate neurons. $a$, p75NTRimmunopanned cells grown in culture $4 \mathrm{~d}$, stained with calcein-AM, and visualized by fluorescence microscopy. $b$, Birth dating of immunopanned cells (black bars) and unbound cells (white bars). A BrdU pulse was given at E12 (birth date of subplate neurons) or E15 (birth date of neurons in layers V and VI), and the percentage of cells labeled with BrdU at E17 was determined. $c$, Percentage of panned cells (black bars) and unbound cells (white bars) immunostained for Tau, vimentin, nestin, or p75NTR. Results are mean \pm SEM.

\section{Signaling through Trk kinases is not required or sufficient for BDNF-dependent survival}

Because p75NTR binds all three neurotrophins, but NGF by itself is without effect, this data suggests that BDNF-dependent survival of subplate neurons might also require the function of ligand-specific Trk receptors in addition to p75NTR. This hy-
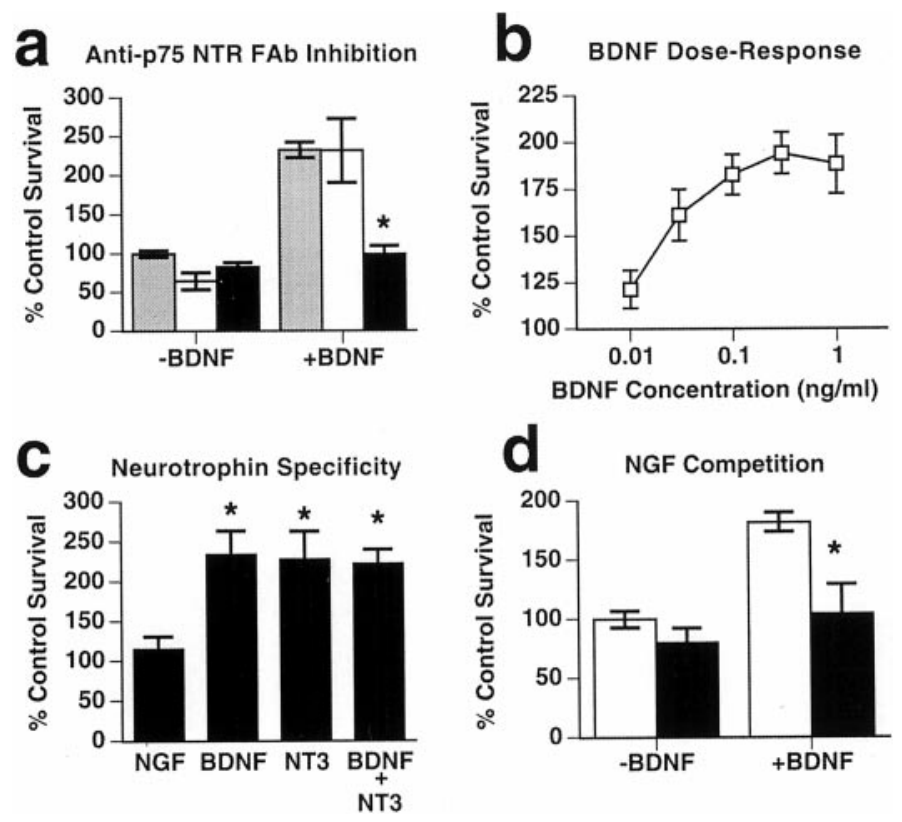

Figure 3. Neurotrophin-mediated survival of subplate neurons is dependent on p75NTR. a, Survival of subplate neurons in the absence or presence of $30 \mathrm{ng} / \mathrm{ml}$ exogenous BDNF. Anti-p75NTR FAbs (black bars) or normal rabbit FAbs (white bars) were added and compared with survival in the absence of FAbs (shaded bars). ${ }^{*} p<0.01$ compared with BDNF with no FAbs. $b$, Dose-response curve for BDNF-dependent survival of subplate neurons. $c$, Survival of panned subplate neurons in the presence of $100 \mathrm{ng} / \mathrm{ml}$ neurotrophins (normalized to neurons grown in the absence of exogenous neurotrophin). ${ }^{*} p<0.01$ compared with control. $d$, Subplate neurons were cultured with BDNF ( $3 \mathrm{ng} / \mathrm{ml})$ with (black bars) or without (white bars) excess NGF $(3 \mu \mathrm{g} / \mathrm{ml}) .{ }^{*} p=0.016$ compared with BDNF alone.

pothesis is supported by the observation that subplate neurons express the Trk receptors for both BDNF and NT3 (TrkB and TrkC, respectively) but not the Trk receptor for NGF TrkA (Fig. 1). To assess the role of Trk tyrosine kinases in subplate neurons, K252a, which potently inhibits several tyrosine kinases including the Trks (Berg et al., 1992), was added to subplate neurons in the presence or absence of neurotrophin. Addition of K252a alone increases the background level of subplate neuron survival. A similar increase in survival by K252a has been shown in studies of cultured sensory, striatal, and basal forebrain neurons and likely results from inhibition of other kinases (Borasio, 1990; Glicksman et al., 1995). However, BDNF and NT3 are still able to further augment survival beyond that of K252a alone (Fig. 4a).

To confirm that Trk activity is completely blocked by K252a, extracts of subplate neurons were probed with an antibody that recognizes all Trks (A, B, and C) phosphorylated at Y490 (Segal et al., 1996; Binder et al., 1999). Because Y490 is autophosphorylated by Trk tyrosine kinases, its phosphorylation state is indicative of Trk activity (Segal et al., 1996). As shown in Figure 4b, treatment of subplate neurons with BDNF results in the robust phosphorylation of Trk at Y490 compared with control. However, K252a completely inhibits the BDNF-dependent phosphorylation of Y490. It is, however, possible that undetectable Trk kinase activity is enough to activate downstream signaling pathways. The Trk tyrosine kinases activate several signaling cascades, including one leading to phosphorylation and activation of MAPK (Segal and Greenberg, 1996). In some types of neurons, including retinal ganglion cells and sympathetic neurons, Trks mediate survival via the activation of this downstream pathway 

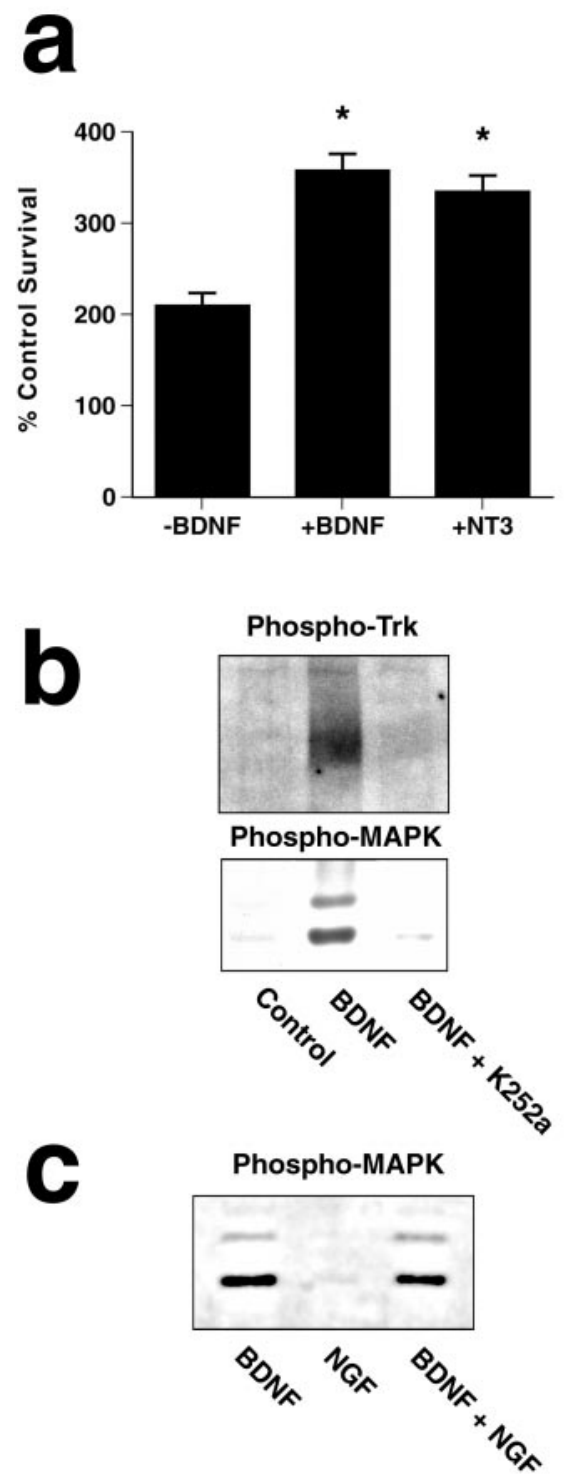

Figure 4. Trk signaling is not necessary for BDNF-dependent survival. $a$, Survival of subplate neurons grown in K252a in the absence or presence of $100 \mathrm{ng} / \mathrm{ml}$ neurotrophins. Data are normalized to survival in the absence of exogenous neurotrophin or K252a. *p $<0.01$ compared with K252a alone; $t$ test. $b$, K252a blocks activation of Trks and MAPK. Extracts of subplate neurons grown in the absence of BDNF or in the presence of BDNF with or without K252a were resolved by Western blot and probed with antibodies to all phosphorylated (i.e., active) Trks or MAPK. $c$, High concentrations of NGF do not activate the MAPK signaling pathway, nor do they block BDNF-dependent activation of MAPK. Western blot of subplate neurons grown in the presence of BDNF, NGF, or both BDNF and NGF and probed with an antibody to phosphorylated MAPK. The concentration of NGF was $3 \mu \mathrm{g} / \mathrm{ml}, 1000-$ fold higher than the concentration of BDNF.

(Meyer-Franke et al., 1998; Bonni et al., 1999; Hetman et al., 1999; Atwal et al., 2000). To verify that this Trk-specific signaling pathway is also blocked by K252a, subplate extracts were probed with an antibody to phosphorylated, and thus active, MAPK. As shown in Figure $4 b$, treatment of subplate neurons with BDNF results in phosphorylation of MAPK, and this phosphorylation is completely blocked by K252a. Thus, K252a blocks the BDNFdependent activation of Trk tyrosine kinases (likely TrkB), as well as downstream signaling pathways. This data argues that Trk signaling by activation of its tyrosine kinase is not necessary for BDNF-enhanced survival. However, this data does not rule out the possibility that Trk receptors may play a role in subplate neuron survival in a novel, non-kinase-dependent manner.

A model consistent with a role for Trks in subplate neuron survival is that p75NTR acts only to facilitate neurotrophin binding and Trk signaling but does not itself signal. This model is suggested by data in other neurons and cell lines that show that p75NTR associates with all three Trks (Bibel et al., 1999), and in the case of NGF, facilitates TrkA signaling at low neurotrophin concentrations (Davies et al., 1993; Lee et al., 1994; Chao et al., 1998). To test this possibility in subplate neurons, we treated subplate neurons with BDNF in the presence of high concentrations of NGF, which competes with BDNF for binding to p75NTR but not to TrkB (Barbacid, 1995). This excess quantity of NGF does not affect neuronal survival or MAPK activation by itself (Figs. 3d, 4c). However, although excess NGF blocks BDNF-dependent survival of subplate neurons (Fig. 3d), it does not affect the BDNF-dependent activation of MAPK, as shown in Figure $4 c$. Thus, the activation of Trk signaling pathways does not require p75NTR, nor are these pathways sufficient to increase subplate neuron survival. Together, these data argue against a role for Trks and instead strongly argue for the importance of p75NTR signaling pathways.

\section{A sphingolipid signaling pathway is required for subplate neuron survival}

Because p75NTR is required for BDNF-mediated subplate neuron survival, known p75NTR signaling pathways were examined in these neurons. p75NTR activates sphingomyelinase, c-Jun $\mathrm{N}$-terminal kinase (JNK), and nuclear translocation of the transcription factor NF $\mathrm{B}$ B in other cell types (Dobrowsky et al., 1994; Carter et al., 1996; Casaccia-Bonnefil et al., 1996). Whereas nuclear $\mathrm{NF} \kappa \mathrm{B}$ binding activity is not detectably affected by treatment of subplate neurons with BDNF, there is a marked increase in JNK phosphorylation by BDNF but not NGF (data not shown). However, BDNF-dependent phosphorylation of JNK is not affected by blocking binding to p75NTR (data not shown). Thus, $\mathrm{NF} \kappa \mathrm{B}$ and $\mathrm{JNKs}$ do not appear to play a central role in p75NTR-mediated survival.

In certain cell types, ligand binding to p75NTR activates sphingomyelinase, an enzyme that converts sphingomyelin to ceramide (Dobrowsky et al., 1994, 1995). Ceramide, in turn, can mediate apoptosis (Casaccia-Bonnefil et al., 1996; Hannun, 1996). Activation of sphingomyelinase is mediated by $\mathrm{p} 75 \mathrm{NTR}$ but not Trk receptors (Dobrowsky et al., 1995). To test the role of this signal transduction pathway in BDNF-mediated subplate neuron survival, we inhibited the synthesis of both ceramide and sphingomyelin. Synthesis of all sphingolipids, including sphingomyelin and ceramide, begins with the conversion of serine to sphinganine and then to $N$-acetylsphinganine. These biosynthetic steps are inhibited by myriocin and the fungal mycotoxin, fumonisin B1, respectively (Merrill et al., 1993; Miyake et al., 1995). Treatment of cerebellar neurons with fumonisin B1 reduces sphingomyelin content drastically (Merrill et al., 1993).

To examine whether regulation of sphingolipid signaling is involved in p75NTR-mediated survival, subplate neurons were grown in either fumonisin or myriocin in the presence or absence of BDNF. Treatment of subplate neurons with fumonisin B1 or myriocin completely abolishes the ability of BDNF to support survival (Fig. $5 a$ ) but does not affect the basal level of survival. Thus, blocking sphingolipid synthesis is not toxic in and of itself. 

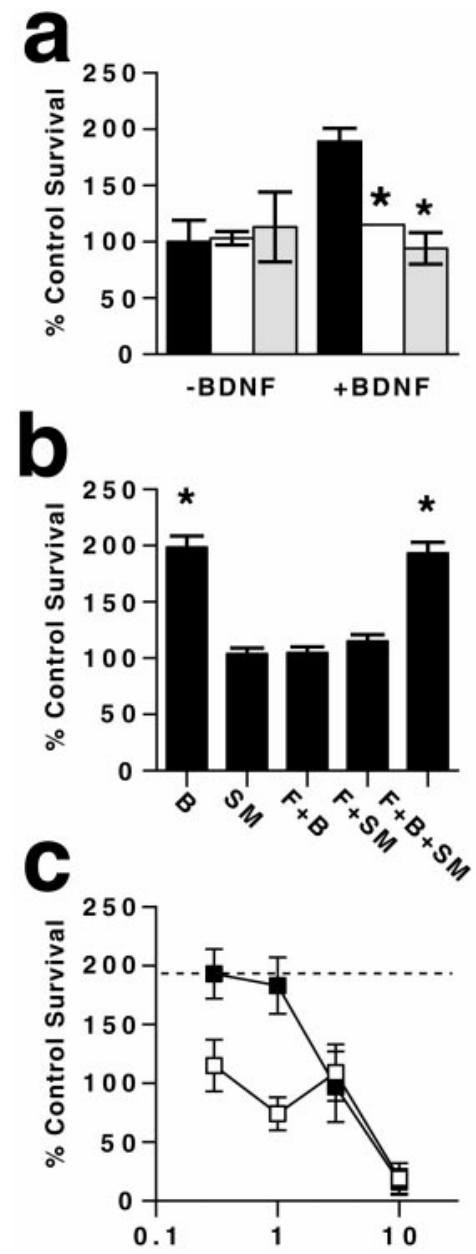

Figure 5. Sphingomyelin synthesis is necessary for p75NTR-dependent survival. $a$, Subplate neurons were cultured with BDNF (black bars) in the presence of fumonisin B1 (white bars) or myriocin (hatched bars). Survival is normalized to that in the absence of additives. ${ }^{*} p<0.01$ compared with BDNF alone. $b$, Survival of subplate neurons grown in the presence of BDNF $(B)$, fumonisin $\mathrm{B} 1(F)$, or sphingomyelin $(S M)$ in combinations indicated. ${ }^{*} p<0.01$ compared with control survival; $t$ test. $c$, Doseresponse curve for sphingomyelin rescue of BDNF-dependent survival. Subplate neurons were grown in the presence of fumonisin and increasing concentrations of sphingomyelin with BDNF (black squares) or without BDNF (white squares). Dashed line represents survival in BDNF alone.

To confirm the specificity of the fumonisin blockade of sphingolipid synthesis, exogenous sphingomyelin was added to subplate neurons grown in the presence of fumonisin B1. In fumonisin B1, neither sphingomyelin nor BDNF alone are able to enhance subplate neuron survival. However, coaddition of BDNF and sphingomyelin to fumonisin-treated neurons increases their survival to levels comparable with that of BDNF in the absence of fumonisin. (Fig. 5b).

To verify that BDNF-dependent survival is not limited by the concentration of sphingomyelin, subplate neurons were grown in fumonisin with increasing concentrations of exogenous sphingomyelin. As shown in Figure 5c, sphingomyelin does not affect the survival of subplate neurons at concentrations as high as $3 \mu \mathrm{M}$ but at $10 \mu \mathrm{M}$ becomes toxic. In this same concentration range, sphingomyelin rescue of BDNF-dependent survival is maximal at 0.3 and $1 \mu \mathrm{M}$ (Fig. $5 c$ ). Survival at these concentrations is equivalent to the level of BDNF-dependent survival in the absence of fumonisin or exogenous sphingomyelin (dotted line). Thus, the sphingomyelin concentration is not limiting for BDNFdependent survival. In addition, increased sphingomyelin levels do not directly promote subplate neuron survival but are a necessary substrate for BDNF-mediated survival, likely through the regulation of sphingomyelinase.

These results provide additional evidence that a p75NTRspecific signaling pathway is necessary for BDNF-dependent survival and provide an unusual example in which p75NTR signaling through the sphingolipid pathway supports neuronal survival, not death.

\section{DISCUSSION}

The results of this study show that ligand binding to p75NTR can promote survival, not death, of a neocortical neuronal population via a sphingolipid signaling pathway. This is surprising in the context of well known examples of neuronal death triggered by ligand-dependent p75NTR activation of ceramide signaling.

Research into the role of p75NTR in neuronal survival has provided contradictory results depending on the type of neurons examined. Studies of mice carrying a gene deletion of p75NTR reveal that it is necessary for survival of sensory and basal forebrain cholinergic neurons, although, conversely, it is necessary for naturally occurring cell death in sympathetic, motor, and retinal neurons (Lee et al., 1992; Bamji et al., 1998; Brennan et al., 1999; Frade and Barde, 1999; Peterson et al., 1999). However, because both neuronal and non-neuronal cells express p75NTR, it is unclear from these studies, as well as studies of unpurified neurons in vitro, whether or not p75NTR functions in a cellautonomous manner for all of these neuronal populations. Our study is thus novel in that we used a highly purified population of CNS neurons cultured at low density, allowing assessment of the direct role of p75NTR and associated signaling pathways on neuronal survival.

\section{p75NTR signaling is required for BDNF-dependent survival}

Although p75NTR-mediated cell death has been linked to the ceramide signaling pathway (Dobrowsky et al., 1994; CasacciaBonnefil et al., 1996), the mechanism of p75NTR-mediated survival is unclear. One model is that p75NTR indirectly promotes survival by facilitating neurotrophin binding to the Trk receptors (Davies et al., 1993; Lee et al., 1994; Chao et al., 1998). The Trk receptor tyrosine kinases, and not p75NTR, then transduce the survival signal. Thus, high concentrations of neurotrophin can support survival even in the absence of p75NTR (Davies et al., 1993; Lee et al., 1994). This mechanism is not consistent with our results in subplate neurons. First, inhibition of Trk phosphorylation with $\mathrm{K} 252 \mathrm{a}$ does not inhibit BDNF-dependent survival. Also, the concentration of BDNF used in conjunction with p75NTR FAbs was 30-fold higher than that required to stimulate Trk-dependent survival maximally in the absence of p75NTR (Davies et al., 1993; Lee et al., 1994). Finally, excess NGF, which competes for binding to p75NTR but not TrkB, blocks BDNFdependent survival but not activation of the Trk-dependent MAPK signaling cascade. Thus, our data strongly support an alternative model that p75NTR directly signals survival in subplate neurons.

A role for p75NTR signaling is further supported by the requirement for sphingolipid synthesis in BDNF-dependent subplate survival. Ligand binding to p75NTR, but not Trk receptors, activates sphingomyelinase, which converts sphingomyelin to ceramide (Dobrowsky et al., 1995). Ceramide in turn acts as a second 
messenger that activates apoptotic pathways in some cell types (Casaccia-Bonnefil et al., 1996; Hannun, 1996). In cells that express both p75NTR and a Trk, coactivation of the high-affinity Trk receptors has been found to suppress p75NTR activation of the ceramide pathway and apoptosis (Dobrowsky et al., 1995; Bamji et al., 1998; Davey and Davies, 1998; Yoon et al., 1998). By this model, the p75NTR apoptotic pathway is only activated by neurotrophins when the Trk receptor tyrosine kinase is not coactivated.

This model, derived from studies of sensory and sympathetic neurons as well as non-neuronal cells, contrasts with our results in subplate neurons in several important respects. First, inhibition of ceramide synthesis prevents BDNF-dependent survival rather than increasing survival, as would be predicted if ceramide mediates cell death. Second, BDNF-dependent survival is rescued by sphingomyelin, the precursor to ceramide. This indicates that p75NTR regulation of sphingomyelinase is a necessary component of BDNF-dependent survival signaling pathway in subplate neurons. This data also suggest that p75NTR promotes survival, not death, by increasing production of ceramide. Finally, because BDNF activates signaling through a Trk kinase (likely TrkB) in subplate neurons (Fig. 4), p75NTR regulation of the ceramide pathway does not appear to be suppressed by a coactivated Trk. The fact that ligand binding to p75NTR is linked to survival in subplate neurons but death in other cell types implies that contradictory roles of p75NTR in vivo may reflect differences in downstream responses to ceramide rather than be solely attributable to the presence or absence of particular Trk receptors.

Our data also rule out the possibility that BDNF promotes survival by decreasing ceramide levels resulting from ligandindependent p75NTR signaling. Ligand-independent p75NTR signaling in response to neurotrophin withdrawal leads, in some cell types, to ceramide production and apoptosis (Bredesen and Rabizadeh, 1997). However, if subplate neurons die from high levels of ceramide resulting from ligand-independent p75NTR signaling, then inhibition of sphingolipid synthesis would be expected to reduce ceramide levels and increase survival. Because survival is not increased by either fumonisin B1 or myriocin, this model is very unlikely. Thus, these observations provide an unusual example in which p75NTR signaling through the sphingolipid pathway supports neuronal survival, not death.

\section{Molecular mechanism of p75NTR signaling}

The molecular details of the p75NTR-activated ceramide signaling cascade are currently only partially understood. p75NTR, by analogy to other members of the TNF receptor family to which it belongs, is thought to initiate signal transduction by clustering within the membrane, causing specific adaptor molecules to associate with its cytoplasmic domain (Dechant and Barde, 1997; Kaplan and Miller, 2000). p75NTR also activates a sphingomyelinase activity in the inner leaflet of the plasma membrane; however, the identity of this sphingomyelinase, as well as how it is coupled to the initial steps in p75NTR signal transduction, is unknown (Dobrowsky et al., 1995). Once activated, sphingomyelinase hydrolyzes sphingomyelin to ceramide. Ceramide then activates JNK, which is linked to the apoptotic cascade in several types of neuronal cells (Casaccia-Bonnefil et al., 1996; Dechant and Barde, 1997; Borasio et al., 1998; Chao et al., 1998; Maroney et al., 1998; Kaplan and Miller, 2000). Examination of JNK knock-out mice, however, reveals that, although JNK is necessary for cell death of neuronal cells in the developing spinal cord, it is required for survival of neuronal cells in developing neocortex
(Kuan et al., 1999). This suggests that one difference between the subplate neurons and the peripheral neurons that have been studied is opposite responses to JNK activation. However, although NGF and anti-p75NTR block BDNF-dependent survival, they do not block the activation of JNK in subplate neurons (our unpublished observations). Therefore, although JNK may play a role in facilitating survival, it does not appear to be sufficient.

Other signaling targets for ceramide that have been identified include protein phosphatase $2 \mathrm{~A}$, protein phosphatase 1 , kinase

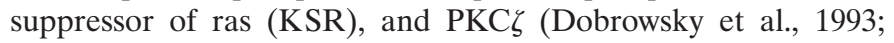
Zhang et al., 1997; Chalfant et al., 1999; Wang et al., 1999; Bourbon et al., 2000). Ceramide activation of KSR modulates the Ras-MAPK pathway in certain non-neuronal cells (Therrien et al., 1996; Sugimoto et al., 1998; Yu et al., 1998) and likely accounts for the p75NTR-dependent activation of MAPK in cerebellar cells (Susen et al., 1999). Although MAPK promotes neurotrophin-dependent survival of several other types of p75NTR-expressing neurons, including retinal neurons (MeyerFranke et al., 1998; Bonni et al., 1999; Hetman et al., 1999; Atwal et al., 2000), it is activated by the Trk receptors, not p75NTR(Kaplan and Miller, 2000). Likewise, MAPK appears to be activated by Trk receptors in subplate neurons as well, because activation of MAPK by BDNF is completely blocked by K252a but not by blocking BDNF binding to p75NTR. Ceramide also directly activates $\mathrm{PKC} \zeta$ at low concentrations, which correlates with increased survival in the PC12 neuronal cell line (Wang et al., 1999). In contrast, high concentrations of ceramide $(>2.5 \mu \mathrm{M})$ inhibit PKC $\zeta$ and increase apoptosis of PC12 cells. Overexpression of $\mathrm{PKC} \zeta$ in these cells enhances survival at high concentrations of ceramide, suggesting that $\mathrm{PKC} \zeta$ plays a direct role in survival. Interestingly, this biphasic response to ceramide, with increased survival at low concentrations and increased apoptosis at high concentrations, has also been observed in motor neurons and hippocampal neurons (Irie and Hirabayashi, 1998; Mitoma et al., 1998). These observations suggest a mechanism that could reconcile the fact that p75NTR signaling causes death in certain neurons and survival in others. If p75NTR causes small increases in the amount of ceramide, survival would be enhanced, possibly through the activation of PKC $\zeta$. Alternatively, if p75NTR causes a large increase in ceramide concentrations, $\mathrm{PKC} \zeta$ would be inhibited and cells would undergo apoptosis.

\section{A possible role for Trks}

Our results show that $\mathrm{p} 75 \mathrm{NTR}$ and ceramide are necessary components of the signaling pathway mediating BDNF-dependent survival of subplate neurons. However, the lack of effect of NGF is surprising because it implies that p75NTR alone (which binds to all neurotrophins) is not sufficient for survival; the Trks must contribute as well to endow specificity for BDNF or NT3 rather than NGF (recall that subplate neurons express TrkB and TrkC but not TrkA). Trks could activate necessary signaling pathways but only in a manner that requires little or no tyrosine kinase activity, because K252a does not block BDNF-mediated survival in our experiments. Alternatively (and in our opinion, more likely) Trks could act solely as coreceptors for p75NTR. Cotransfection experiments in A293 cells demonstrate that p75NTR can associate with both TrkB and TrkC (Bibel et al., 1999). In other experiments, transfection of truncated TrkC (lacking the tyrosine kinase domain) into p75NTR-expressing neural crest cells resulted in NT3-specific signaling that was blocked by p75NTRspecific antibodies (Hapner et al., 1998). This observation has been interpreted to indicate signaling through truncated $\mathrm{TrkC}$, 
but alternatively, it could be interpreted as Trk-facilitated signaling through p75NTR.

\section{Role of P75NTR in vivo}

The in vitro results presented here suggest that p75NTR plays a role in subplate neuron survival in vivo. Consistent with this hypothesis, p75NTR expression by subplate neurons is high during the period when they are alive and functioning in cortical circuits and then is downregulated just before their death in vivo (Allendoerfer et al., 1990; Meinecke and Rakic, 1993). Because only subplate neurons, and not cortical neurons, express p75NTR, this could be an elegant mechanism whereby one class of cortical neurons can be selectively eliminated from a cellular environment shared by all. However, preliminary experiments have not revealed an increased loss of subplate neurons in mice with the p75NTR gene knocked out (our unpublished observations), which suggests that subplate survival is controlled by multiple tropic factor receptors. One possible candidate is NT3, because, as shown in Figure 1, subplate neurons express the NT3-specific receptor, TrkC. In support of this hypothesis, we have found that NT3-dependent subplate neuron survival in vitro is only blocked by a combination of K252a and anti-p75NTR antibodies and not by either reagent alone (our unpublished observations). Thus, whereas BDNF requires the p75NTR signaling pathway to promote survival, NT3 can signal through either Trk (likely TrkC) or p75NTR.

Although our study is of subplate neurons in vitro, these results imply that a novel p75NTR signaling pathway contributes to subplate neuron survival in vivo. Another cortical neuron population that expresses p75NTR in maturity are the basal forebrain cholinergic neurons (Woolf et al., 1989). These neurons are dependent on p75NTR for survival and are lost in neurodegenerative diseases, such as Alzheimer's disease (Geula, 1998; Peterson et al., 1999). Our observations here raise the possibility that these CNS neurons, like subplate neurons, use this p75NTR signaling pathway for survival in vivo. Thus, activation of this sphingolipid signaling pathway might provide a useful therapeutic approach for rescuing these neurons.

\section{REFERENCES}

Alcántara S, Frisén J, del Río JA, Soriano E, Barbacid M, Silos-Santiago I (1997) TrkB signaling is required for postnatal survival of CNS neurons and protects hippocampal and motor neurons from axotomyinduced cell death. J Neurosci 17:3623-3633.

Allendoerfer KL, Shatz CJ (1994) The subplate, a transient neocortical structure: its role in the development of connections between thalamus and cortex. Annu Rev Neurosci 17:185-218.

Allendoerfer KL, Shelton DL, Shooter EM, Shatz CJ (1990) Nerve growth factor receptor immunoreactivity is transiently associated with the subplate neurons of the mammalian cerebral cortex. Proc Natl Acad Sci USA 87:187-190.

Atwal JK, Massie B, Miller FD, Kaplan DR (2000) The TrkB-Shc site signals neuronal survival and local axon growth via MEK and P13kinase. Neuron 27:265-277.

Bamji SX, Majdan M, Pozniak CD, Belliveau DJ, Aloyz R, Kohn J, Causing CG, Miller FD (1998) The p75 neurotrophin receptor mediates neuronal apoptosis and is essential for naturally occurring sympathetic neuron death. J Cell Biol 140:911-923.

Barbacid M (1995) Neurotrophic factors and their receptors. Curr Opin Cell Biol 7:148-155.

Barres BA, Silverstein BE, Corey DP, Chun LL (1988) Immunological, morphological, and electrophysiological variation among retinal ganglion cells purified by panning. Neuron 1:791-803.

Bayer SA, Altman J (1990) Development of layer I and the subplate in the rat neocortex. Exp Neurol 107:48-62.

Berg MM, Sternberg DW, Parada LF, Chao MV (1992) K-252a inhibits nerve growth factor-induced trk proto-oncogene tyrosine phosphorylation and kinase activity. J Biol Chem 267:13-16.

Bibel M, Hoppe E, Barde YA (1999) Biochemical and functional inter- actions between the neurotrophin receptors trk and p75NTR. EMBO J 18:616-622.

Bignami A, Raju T, Dahl D (1982) Localization of vimentin, the nonspecific intermediate filament protein, in embryonal glia and in early differentiating neurons. In vivo and in vitro immunofluorescence study of the rat embryo with vimentin and neurofilament antisera. Dev Biol 91:286-295.

Binder DK, Routbort MJ, McNamara JO (1999) Immunohistochemical evidence of seizure-induced activation of trk receptors in the mossy fiber pathway of adult rat hippocampus. J Neurosci 19:4616-4626.

Bonni A, Brunet A, West AE, Datta SR, Takasu MA, Greenberg ME (1999) Cell survival promoted by the Ras-MAPK signaling pathway by transcription-dependent and -independent mechanisms. Science 286:1358-1362.

Borasio GD (1990) Differential effects of the protein kinase inhibitor K-252a on the in vitro survival of chick embryonic neurons. Neurosci Lett 108:207-212.

Borasio GD, Horstmann S, Anneser JM, Neff NT, Glicksman MA (1998) CEP-1347/KT7515, a JNK pathway inhibitor, supports the in vitro survival of chick embryonic neurons. NeuroReport 9:1435-1439.

Bourbon NA, Yun J, Kester M (2000) Ceramide directly activates PKC zeta to regulate a stress-activated protein kinase signaling complex. J Biol Chem 275:35617-35623.

Bredesen DE, Rabizadeh S (1997) p75NTR and apoptosis: Trkdependent and Trk-independent effects. Trends Neurosci 20:287-290.

Brennan C, Rivas-Plata K, Landis SC (1999) The p75 neurotrophin receptor influences NT-3 responsiveness of sympathetic neurons in vivo. Nat Neurosci 2:699-705.

Cabelli RJ, Allendoerfer KL, Radeke MJ, Welcher AA, Feinstein SC, Shatz CJ (1996) Changing patterns of expression and subcellular localization of TrkB in the developing visual system. J Neurosci 16:7965-7980.

Carter BD, Lewin GR (1997) Neurotrophins live or let die: does p75NTR decide? Neuron 18:187-190.

Carter BD, Kaltschmidt C, Kaltschmidt B, Offenhäuser N, BöhmMatthaei R, Baeuerle PA, Barde YA (1996) Selective activation of NF-kappa B by nerve growth factor through the neurotrophin receptor p75. Science 272:542-545.

Casaccia-Bonnefil P, Carter BD, Dobrowsky RT, Chao MV (1996) Death of oligodendrocytes mediated by the interaction of nerve growth factor with its receptor p75. Nature 383:716-719.

Chalfant CE, Kishikawa K, Mumby MC, Kamibayashi C, Bielawska A, Hannun YA (1999) Long chain ceramides activate protein phosphatase-1 and protein phosphatase-2A. Activation is stereospecific and regulated by phosphatidic acid. J Biol Chem 274:20313-20317.

Chandler CE, Parsons LM, Hosang M, Shooter EM (1984) A monoclonal antibody modulates the interaction of nerve growth factor with PC12 cells. J Biol Chem 259:6882-6889.

Chao M, Casaccia-Bonnefil P, Carter B, Chittka A, Kong H, Yoon SO (1998) Neurotrophin receptors: mediators of life and death. Brain Res Brain Res Rev 26:295-301.

Chen KS, Nishimura MC, Armanini MP, Crowley C, Spencer SD, Phillips HS (1997) Disruption of a single allele of the nerve growth factor gene results in atrophy of basal forebrain cholinergic neurons and memory deficits. J Neurosci 17:7288-7296.

Conover JC, Yancopoulos GD (1997) Neurotrophin regulation of the developing nervous system: analyses of knockout mice. Rev Neurosci $8: 13-27$.

Corriveau RA, Huh GS, Shatz CJ (1998) Regulation of class I MHC gene expression in the developing and mature CNS by neural activity. Neuron 21:505-520.

Davey F, Davies AM (1998) TrkB signalling inhibits p75-mediated apoptosis induced by nerve growth factor in embryonic proprioceptive neurons. Curr Biol 8:915-918.

Davies AM, Lee KF, Jaenisch R (1993) p75-deficient trigeminal sensory neurons have an altered response to NGF but not to other neurotrophins. Neuron 11:565-574.

Dechant G, Barde YA (1997) Signalling through the neurotrophin receptor p75NTR. Curr Opin Neurobiol 7:413-418.

Dobrowsky RT, Kamibayashi C, Mumby MC, Hannun YA (1993) Ceramide activates heterotrimeric protein phosphatase $2 \mathrm{~A}$. J Biol Chem 268:15523-15530.

Dobrowsky RT, Werner MH, Castellino AM, Chao MV, Hannun YA (1994) Activation of the sphingomyelin cycle through the low-affinity neurotrophin receptor. Science 265:1596-1599.

Dobrowsky RT, Jenkins GM, Hannun YA (1995) Neurotrophins induce sphingomyelin hydrolysis. Modulation by co-expression of p75NTR with Trk receptors. J Biol Chem 270:22135-22142.

Fagan AM, Garber M, Barbacid M, Silos-Santiago I, Holtzman DM (1997) A role for TrkA during maturation of striatal and basal forebrain cholinergic neurons in vivo. J Neurosci 17:7644-7654.

Ferreira A, Busciglio J, Cáceres A (1987) An immunocytochemical analysis of the ontogeny of the microtubule-associated proteins MAP-2 and Tau in the nervous system of the rat. Brain Res 431:9-31.

Frade JM, Barde YA (1999) Genetic evidence for cell death mediated by 
nerve growth factor and the neurotrophin receptor p75 in the developing mouse retina and spinal cord. Development 126:683-690.

Friauf E, McConnell SK, Shatz CJ (1990) Functional synaptic circuits in the subplate during fetal and early postnatal development of cat visual cortex. J Neurosci 10:2601-2613.

Geula C (1998) Abnormalities of neural circuitry in Alzheimer's disease: hippocampus and cortical cholinergic innervation. Neurology 51:S18S29; discussion S65-S67.

Ghosh A, Shatz CJ (1993) A role for subplate neurons in the patterning of connections from thalamus to neocortex. Development 117:1031-1047.

Ghosh A, Antonini A, McConnell SK, Shatz CJ (1990) Requirement for subplate neurons in the formation of thalamocortical connections. Nature 347:179-181.

Glicksman MA, Forbes ME, Prantner JE, Neff NT (1995) K-252a promotes survival and choline acetyltransferase activity in striatal and basal forebrain neuronal cultures. J Neurochem 64:1502-1512.

Hannun YA (1996) Functions of ceramide in coordinating cellular responses to stress. Science 274:1855-1859.

Hapner SJ, Boeshore KL, Large TH, Lefcort F (1998) Neural differentiation promoted by truncated trkC receptors in collaboration with p75(NTR). Dev Biol 201:90-100.

Hetman M, Kanning K, Cavanaugh JE, Xia Z (1999) Neuroprotection by brain-derived neurotrophic factor is mediated by extracellular signal-regulated kinase and phosphatidylinositol 3-kinase. J Biol Chem 274:22569-22580

Huettner JE, Baughman RW (1986) Primary culture of identified neurons from the visual cortex of postnatal rats. J Neurosci 6:3044-3060.

Irie F, Hirabayashi Y (1998) Application of exogenous ceramide to cultured rat spinal motoneurons promotes survival or death by regulation of apoptosis depending on its concentrations. J Neurosci Res 54:475-485.

Kaplan DR, Miller FD (2000) Neurotrophin signal transduction in the nervous system. Curr Opin Neurobiol 10:381-391.

Kaplan DR, Hempstead BL, Martin-Zanca D, Chao MV, Parada LF (1991) The trk proto-oncogene product: a signal transducing receptor for nerve growth factor. Science 252:554-558.

Klein R, Parada LF, Coulier F, Barbacid M (1989) trkB, a novel tyrosine protein kinase receptor expressed during mouse neural development. EMBO J 8:3701-3709.

Koh S, Loy R (1989) Localization and development of nerve growth factor-sensitive rat basal forebrain neurons and their afferent projections to hippocampus and neocortex. J Neurosci 9:2999-3018.

Kuan CY, Yang DD, Samanta Roy DR, Davis RJ, Rakic P, Flavell RA (1999) The Jnk1 and Jnk2 protein kinases are required for regional specific apoptosis during early brain development. Neuron 22:667-676.

Lamballe F, Klein R, Barbacid M (1991) trkC, a new member of the trk family of tyrosine protein kinases, is a receptor for neurotrophin-3. Cell 66:967-979.

Lee KF, Li E, Huber LJ, Landis SC, Sharpe AH, Chao MV, Jaenisch R (1992) Targeted mutation of the gene encoding the low affinity NGF receptor p 75 leads to deficits in the peripheral sensory nervous system. Cell 69:737-749.

Lee KF, Davies AM, Jaenisch R (1994) p75-deficient embryonic dorsal root sensory and neonatal sympathetic neurons display a decreased sensitivity to NGF. Development 120:1027-1033.

Lendahl U, Zimmerman LB, McKay RD (1990) CNS stem cells express a new class of intermediate filament protein. Cell 60:585-595.

Maroney AC, Glicksman MA, Basma AN, Walton KM, Knight Jr E, Murphy CA, Bartlett BA, Finn JP, Angeles T, Matsuda Y, Neff NT, Dionne CA (1998) Motoneuron apoptosis is blocked by CEP-1347 (KT 7515), a novel inhibitor of the JNK signaling pathway. J Neurosci 18:104-111.

Meinecke DL, Rakic P (1993) Low-affinity p75 nerve growth factor receptor expression in the embryonic monkey telencephalon: timing and localization in diverse cellular elements. Neuroscience 54:105-116. Merrill Jr AH, van Echten G, Wang E, Sandhoff K (1993) Fumonisin B1 inhibits sphingosine (sphinganine) $N$-acyltransferase and de novo sphingolipid biosynthesis in cultured neurons in situ. J Biol Chem 268:27299-27306.

Meyer-Franke A, Wilkinson GA, Kruttgen A, Hu M, Munro E, Hanson Jr MG, Reichardt LF, Barres BA (1998) Depolarization and cAMP elevation rapidly recruit TrkB to the plasma membrane of CNS neurons. Neuron 21:681-693.

Minichiello L, Klein R (1996) TrkB and TrkC neurotrophin receptors cooperate in promoting survival of hippocampal and cerebellar granule neurons. Genes Dev 10:2849-2858.

Mitoma J, Ito M, Furuya S, Hirabayashi Y (1998) Bipotential roles of ceramide in the growth of hippocampal neurons: promotion of cell survival and dendritic outgrowth in dose- and developmental stagedependent manners. J Neurosci Res 51:712-722.

Miyake Y, Kozutsumi Y, Nakamura S, Fujita T, Kawasaki T (1995) Serine palmitoyltransferase is the primary target of a sphingosine-like immunosuppressant, ISP-1/myriocin. Biochem Biophys Res Commun 211:396-403.

Peterson DA, Dickinson-Anson HA, Leppert JT, Lee KF, Gage FH (1999) Central neuronal loss and behavioral impairment in mice lacking neurotrophin receptor p75. J Comp Neurol 404:1-20.

Price DJ, Aslam S, Tasker L, Gillies K (1997) Fates of the earliest generated cells in the developing murine neocortex. J Comp Neurol 377:414-422.

Radeke MJ, Misko TP, Hsu C, Herzenberg LA, Shooter EM (1987) Gene transfer and molecular cloning of the rat nerve growth factor receptor. Nature 325:593-597.

Schnitzer J, Franke WW, Schachner M (1981) Immunocytochemical demonstration of vimentin in astrocytes and ependymal cells of developing and adult mouse nervous system. J Cell Biology 90:435-447.

Segal RA, Greenberg ME (1996) Intracellular signaling pathways activated by neurotrophic factors. Annu Rev Neurosci 19:463-489.

Segal RA, Bhattacharyya A, Rua LA, Alberta JA, Stephens RM, Kaplan DR, Stiles CD (1996) Differential utilization of Trk autophosphorylation sites. J Biol Chem 271:20175-20181.

Spreafico R, Frassoni C, Arcelli P, Selvaggio M, De Biasi S (1995) In situ labeling of apoptotic cell death in the cerebral cortex and thalamus of rats during development. J Comp Neurol 363:281-295.

Sugimoto T, Stewart S, Han M, Guan KL (1998) The kinase suppressor of Ras (KSR) modulates growth factor and Ras signaling by uncoupling Elk-1 phosphorylation from MAP kinase activation. EMBO J 17:1717-1727.

Susen K, Heumann R, Blochl A (1999) Nerve growth factor stimulates MAPK via the low affinity receptor p75(LNTR). FEBS Lett 463:231-234.

Therrien M, Michaud NR, Rubin GM, Morrison DK (1996) KSR modulates signal propagation within the MAPK cascade. Genes Dev 10:2684-2695.

Wang YM, Seibenhener ML, Vandenplas ML, Wooten MW (1999) Atypical PKC zeta is activated by ceramide, resulting in coactivation of NF-kappaB/JNK kinase and cell survival. J Neurosci Res 55:293-302.

Weskamp G, Reichardt LF (1991) Evidence that biological activity of NGF is mediated through a novel subclass of high affinity receptors. Neuron 6:649-663.

Woolf NJ, Gould E, Butcher LL (1989) Nerve growth factor receptor is associated with cholinergic neurons of the basal forebrain but not the pontomesencephalon. Neuroscience 30:143-152.

Yoon SO, Casaccia-Bonnefil P, Carter B, Chao MV (1998) Competitive signaling between TrkA and $\mathrm{p} 75$ nerve growth factor receptors determines cell survival. J Neurosci 18:3273-3281.

Yu W, Fantl WJ, Harrowe G, Williams LT (1998) Regulation of the MAP kinase pathway by mammalian $\mathrm{Ksr}$ through direct interaction with MEK and ERK. Curr Biol 8:56-64.

Zhang Y, Yao B, Delikat S, Bayoumy S, Lin XH, Basu S, McGinley M, Chan-Hui PY, Lichenstein H, Kolesnick R (1997) Kinase suppressor of Ras is ceramide-activated protein kinase. Cell 89:63-72. 